Article

\title{
Asymmetric Frontal Response across the Gulf of Mexico Front in Winter 2016
}

\author{
Mohammad Barzegar ${ }^{1, * \mathbb{D}}$, Darek Bogucki ${ }^{1}$, Brian K. Haus ${ }^{2}$, Tamay Ozgokmen ${ }^{2}$ and Mingming Shao ${ }^{2}(\mathbb{D}$ \\ 1 Department of Physical and Environmental Sciences, Texas A\&M University-Corpus Christi, \\ Corpus Christi, TX 78412, USA; Darek.Bogucki@tamucc.edu \\ 2 Rosenstiel School of Marine and Atmospheric Science, University of Miami, \\ Miami, FL 33149, USA; bhaus@rsmas.miami.edu (B.K.H.); tozgokmen@rsmas.miami.edu (T.O.); \\ mshao@rsmas.miami.edu (M.S.) \\ * Correspondence: Mbarzegarpaiinlamouk@islander.tamucc.edu
}

Citation: Barzegar, M.; Bogucki, D.; Haus, B.; Ozgokmen, T; Shao, M. Asymmetric Frontal Response across the Gulf of Mexico Front in Winter 2016. J. Mar. Sci. Eng. 2021, 9, 402. https://doi.org/10.3390/jmse9040402

Academic Editor: Francesca De Serio

Received: 22 March 2021

Accepted: 6 April 2021

Published: 9 April 2021

Publisher's Note: MDPI stays neutral with regard to jurisdictional claims in published maps and institutional affiliations.

Copyright: (c) 2021 by the authors. Licensee MDPI, Basel, Switzerland. This article is an open access article distributed under the terms and conditions of the Creative Commons Attribution (CC BY) license (https:// creativecommons.org/licenses/by/ $4.0 /)$.
Abstract: The interaction of cold-vertically stratified (CVS) Mississippi River water with warmhorizontally stratified (WHS) Gulf of Mexico water resulted in a front that affected the oceanic surface layer. Our cross-frontal observations demonstrated two vertical layers. The cross-frontal deep layer (9-30 m) averaged a temperature dissipation rate (TD) varied by a factor of 1000 and was larger on the CVS side. The near-surface layer (0-9 m) averaged TD did not vary significantly across the front. The deep layer frontal asymmetry coincided with depths where the Thorpe scale was large. The situation was similar for the layer averaged turbulent kinetic energy dissipation rate (TKED). Within both layers, the averaged-TKED values were 10-30 times larger on the CVS side. The surface turbulent heat flux was up to 4 times larger on the WHS side. The observed asymmetric response of the turbulence across the front could play a significant role in the ocean-atmosphere climate system.

Keywords: front; turbulence; heat flux; gulf of mexico

\section{Introduction}

The Lateral gradient of density caused by temperature and/or salinity gradients, with a distinct boundary between two water masses, make up oceanic fronts [1]. Fronts are observed frequently across the global ocean such as: The Gulf Stream [2], the Agulhas Current [3], the Kuroshio Extension [4], and the northern part of the Gulf of Mexico (GOM) [5]. Fronts have an essential role of the energy cycle in the ocean and strengthen and modify the turbulent boundary layer rather than the atmospheric forcing [6]. The turbulence generated by the mesoscale front $(10-1000 \mathrm{~km})$ and submesoscale front $(0.1-10 \mathrm{~km})$ is an essential source of subduction and upwelling at the ocean boundary layer [7], and on the effects of heat fluxes [8], biogeochemical cycles [9], air-sea gas transfer [10], and petroleum pollution [11,12].

Observations of the front at the Kuroshio current by D'Asaro et al. [6] indicated that the turbulent kinetic energy dissipation rate (TKED) within the frontal mixed layer is enhanced by one to two orders of magnitude. Nagai et al. [13] have done direct observations on both sides of the Kuroshio front between 0.2-1.2 $\times$ MLD (mixed layer depth), contrary to the observations made by D'Asaro et al. [6], they investigate TKED at the front without separating both sides from each other. Nagai et al. [13] indicated that the TKED are an order of magnitude larger than predicted by wind scaling in the south of the front, while D'Asaro et al. [6] observed that the wind and surface cooling could not explain the high turbulence level at the front. The observations by Oakey and Elliott [14], and Inoue et al. [15] found that large TKED values within the front can be attributed to internal wave (IW) breaking. However, the detailed mechanisms responsible for the enhanced value of TKED, turbulent fluxes, and mixing across the front remain unclear and need more detailed observations, especially within the upper mixed layer. 
For this reason, the high-resolution microstructure measurements were used to address the turbulence variability on both sides of a submesoscale front from the water surface to $0.4 \times$ MLD. This paper aims to quantify horizontal and vertical TKED and temperature dissipation (TD) rate variability across the front and their vertical transport effects. The paper is organized as follows: The field overview, the observation location, and instruments are introduced in Sections 2 and 3, followed by the results and discussion in Sections 4 and 5. The conclusion is presented in Section 6.

\section{Overview of the Field Experiment}

Data presented in this paper were collected during the LAgrangian Submesoscale ExpeRiment (LASER) in the northern part of the GOM during the winter of 2016 (Figure 1). LASER was undertaken by CARTHE (Consortium for Advanced Research on Transport of Hydrocarbons in the Environment) as a large scale study of oceanic surface lagrangian transport and dispersion. The R/V Walton Smith was used during LASER as a main mobile oceanographic and atmospheric sensor platform. As a part of the experiment, we have documented the presence of a submesoscale front generated by the interaction of cold Mississippi river water with continental shelf water, which may be affected by the warm loop current generated in the GOM [16-18]. An investigation of the processes and instabilities in northern GOM with a regional model using submesoscale and mesoscale numerical simulations suggested that the Mississippi river water interaction with loop current eddies is the primary driver of the front [5]. Luo et al. [5] also argued that the fronts are generated primarily by frontogenesis and mixed layer instabilities in winter, while in summer, the frontogenesis fueled by the horizontal density gradients generated by the river is the dominant driver. A detailed overview of frontal dynamics during LASER are in McWilliams [19], D'Asaro et al. [20], Barkan et al. [21], and D'Asaro et al. [22].

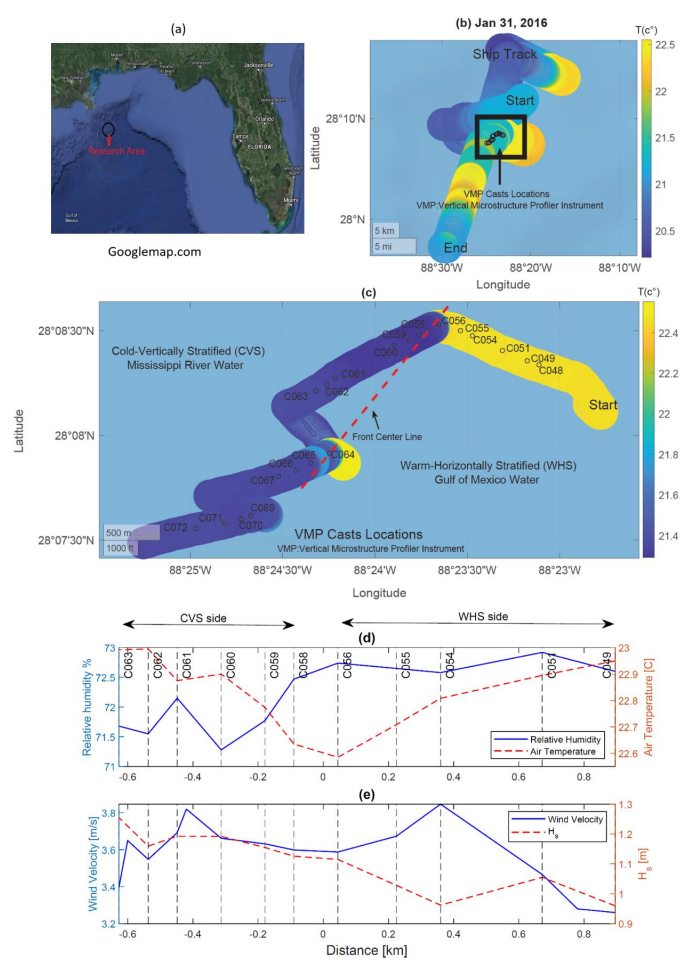

Figure 1. (a) The location of data collection in the northern part of the Gulf of Mexico (GOM). (b) The surface temperature colors the ship track. (c) The subdomain of the ship track where the VMP200 collected the vertical profiles of ocean properties is shown. The dashed red line shows the relative locations of the front center. (d) The relative humidity, (d) the air temperature, (e) the wind velocity, and (e) significant wave height, $\mathrm{H}_{5}$, are presented across the front. The vertical dashed-lines in graphs (d,e) give the horizontal distance of the VMP200 deployments for upcasts C049 to C063 from the front center shown by zero distance. 


\section{Experimental Methods}

The University of Miami research vessel, R/V Walton Smith, provides a stable platform for oceanic turbulence, hydrographic, and air-sea flux sampling. During LASER, the vessel passed over the front (Figure 1). The hydrographic and atmospheric data collected by the ship are presented in Figure 1d,e and includes the relative humidity, air temperature, wind velocity, and significant wave height $\left(\mathrm{H}_{S}\right)$. The water surface elevation was observed by the ultrasonic distance meter (UDMS, Senix ToughSonic). The ship's motion and rotation were measured using linear accelerometers (Columbia Research Model AS-307 HPTX) and rotation rate gyros (SYSTRON Donner QRS11-00050-630), respectively. The method of Drennan et al. [23] was used to calculate the actual surface wave height. In this method, the displacement of the wave created by ship motion and rotation was corrected. The ultrasonic anemometer (RM Young 81000) was mounted at $4.6 \mathrm{~m}$ above the water surface to measure the wind speed, and a Campbell Scientific IRGASON was mounted at $5.36 \mathrm{~m}$ above the water surface to measure the relative humidity and air temperature. The surface roughness was measured by a Helmholtz-Zentrum Geesthacht Marine X-band Radar (MR) mounted on top of the wheelhouse covering a $360^{\circ}$ azimuthal range. The hydrographic data collection method is described in detail in the work of Shao et al. [17].

We present results from 13 of the 97 vertical turbulence profiles across the submesoscale front. The turbulence data were collected with the aid of a Rockland Scientific vertical microstructure profiler (VMP200) [24,25]. The VMP200 was equipped with two orthogonally-oriented shear sensors. Each shear sensor sampled the small-scale shear in horizontal velocity with a $512-\mathrm{Hz}$ sampling rate. The VMP200 was also equipped with a fast thermistor (model FP07, $7 \mathrm{~ms}$ response time, and sampled at $512 \mathrm{~Hz}$ ) and fast conductivity sensor (Sea-Bird SBE7 response time less than $1 \mathrm{~ms}$, sampled at $512 \mathrm{~Hz}$ ).

The VMP200 was deployed in two modes: Free-falling and free-uprising. In the freefalling mode or the downcast mode, the VMP200 is negatively buoyant. In this mode, while deployed from the ship's deck, the VMP200 was permitted to free fall to a depth $\approx 110 \mathrm{~m}$ which was beneath the seasonal mixed layer depth. In downcast mode, we only report data only from depths $z>5 \mathrm{~m}$ to avoid the contamination of TKED and TD near-surface data by the ship wake [25]. The terminal velocity of the VMP200 while in free fall was around $0.72 \mathrm{~m} / \mathrm{s}$.

To sample the near-surface part of the water column, we used the VMP200 in a free uprising mode or the upcast mode [25]. The VMP200 system included a buoyancy collar, to make it positively buoyant and a remote-controlled weight release mechanism. The release of the weight freed the VMP200 to start freely rising towards the surface. The data presented here were collected when the uprising VMP200 attained its terminal velocity of $0.65 \mathrm{~m} / \mathrm{s}$. The free rising deployment methodology was as follows: We first lowered the instrument to a predetermined depth, typically around $40 \mathrm{~m}$. While the ship was in a slow wind-induced drift, we then waited until the ship left the area where the VMP200 would likely emerge. Once the ship was relatively far away from the VMP200, we released the weight, freeing the VMP200 to rise towards the surface.

This approach permitted us to sample the near-surface in more detail, while the VMP200 traveled vertically at its terminal velocity. The upcast deployments that were recovered close to the ship $(<100 \mathrm{~m})$ were eliminated. The VMP200 data were processed using the standard approach [25], and we converted temporal shear gradients to corresponding spatial gradients by invoking Taylor's frozen field hypothesis [25]. The profiles presented here were characterized by a VMP200 shear sensor observed attack angle $<10 \mathrm{deg}$. All presented data were quality controlled for factors affecting the TKED data quality such as attack angle and spikes [25]. 
Following the standard assumption that the oceanic flow can be approximated by idealized homogenous and isotropic turbulence, the TKED (or $\epsilon$ ) can be derived from the VMP200 measured shear spectrum $\Psi(K)$ as [25,26]: $\epsilon=15 / 2 v \int_{0}^{\infty} \Psi(K) d K$, where $K$ is the wavenumber, and $v$ is the kinematic viscosity. The TD (or $\chi$ ) can be obtained from the VMP200, measured one dimensional temperature gradient spectra, $\phi(K)$, as [27,28]: $\chi=6 K_{\theta} \int_{0}^{\infty} \phi(K) d K$, where $K_{\theta}$ is the thermal molecular diffusivity. The FP07 thermistor used in the VMP200 does not fully resolve the temperature variance of the underlying temperature field when traveling through the water column faster than $0.1 \mathrm{~m} / \mathrm{s}$ (Lueck 1977). In our measurements presented here, the terminal VMP200 rising speed was $\approx 0.65 \mathrm{~m} / \mathrm{s}$. The VMP200 measured vertical TD profiles thus represent underestimates of the 'real' water column TD, as we did not correct the TD by the FP07 spectral response function [24] (Figure 2b).

The VMP200 upcasts method permitted very accurate observations of the near-surface layer as the VMP200 rise velocity was constant at $0.65 \mathrm{~m} / \mathrm{s}$ until it reached the surface with a vertical bin resolution of $\approx 1 \mathrm{~mm}$ for salinity and temperature and $\approx 0.5 \mathrm{~m}$ for TD and TKED data. The VMP200 consecutive casts, denoted as C048-C072, were collected on 31 January, 2016 with a time interval of less than $10 \mathrm{~min}$ between each profile (Figure 1). The casts C048-C056 and C058-C072 were collected on the cold-vertically stratified (CVS) and warm-horizontally stratified (WHS) sides, respectively. The front center was assumed to be the midpoint of the region where the sea surface temperature changed by $1.5{ }^{\circ} \mathrm{C}$ over $5 \mathrm{~km}$ [17]. The front center's location was estimated from the surface roughness variability (measured by ship-based marine radar [17]) and coincided with the VMP200 cast C064.

\section{Results}

The air-side data collected during the front transect are presented in Figure 1d,e. The relative humidity on the WHS side (relative humidity is $72.65 \%$ ) was on average $0.5 \%$ higher than the CVS side (relative humidity is $71.92 \%$ ) (Figure 1d). On the WHS side, the air temperature dropped from $\approx 22.90^{\circ} \mathrm{C}$, at C049, to $\approx 22.60{ }^{\circ} \mathrm{C}$, at C056 while on the CVS side, the air temperature was increased with distance from the front center, and reached to $\approx 23{ }^{\circ} \mathrm{C}$, at $\mathrm{C} 063$. The average air temperature was approximately the same on both sides of the front (Figure 1d). The dominant wind direction was across the front from the WHS side to the CVS side. The wind velocity increased from $\approx 3.25 \mathrm{~m} / \mathrm{s}$, at C048, to $\approx 3.67 \mathrm{~m} / \mathrm{s}$, at C060, then it decreased to $\approx 3.45 \mathrm{~m} / \mathrm{s}$, at C063 (Figure 1e). The average significant wave height, $H_{s}$, on the CVS side $\left(H_{s}=1.20 \mathrm{~m}\right)$ was $\approx 15 \%$ larger than the WHS side $\left(H_{s}=1.05 \mathrm{~m}\right)$ (Figure 1e). In Figures $1-4$, the vertical dashed lines present the location of the VMP200 deployments. The distance ' 0 ' coincides with the front center.

\subsection{Mixed Layer Depth-The VMP200 Downcasts}

The VMP downcast technique was used to study the ocean water column through the mixed layer depth (MLD). The downcast profiles of C071 and C072 are shown in Figure 2a-c. The measured TKED and TD values decreased by about three orders of magnitude from $z=5 \mathrm{~m}$ to a depth of $z=55 \mathrm{~m}$. TKED and TD attained their maximum values of $\epsilon \approx 1.45 \times 10^{-6} \mathrm{~W} / \mathrm{kg}$ (Nagai et al. [4] observed $\epsilon \approx 10^{-8}-10^{-6} \mathrm{~W} / \mathrm{kg}$ in the Kuroshio front) and $\chi \approx 2 \times 10^{-4}{ }^{\circ} \mathrm{C} / \mathrm{s}$, within the depth interval $\approx 8-10 \mathrm{~m}$. The density profile (Figure 2c) showed a large density variance over depths from $3 \mathrm{~m}$ to around $9 \mathrm{~m}$. The observed seasonal mixed layer depth was found to be around $80 \mathrm{~m}$ when using the criteria [29] corresponding to the change of density $\Delta \rho=0.03 \mathrm{~kg} / \mathrm{m}^{3}$ over a $10-\mathrm{m}$ depth. 

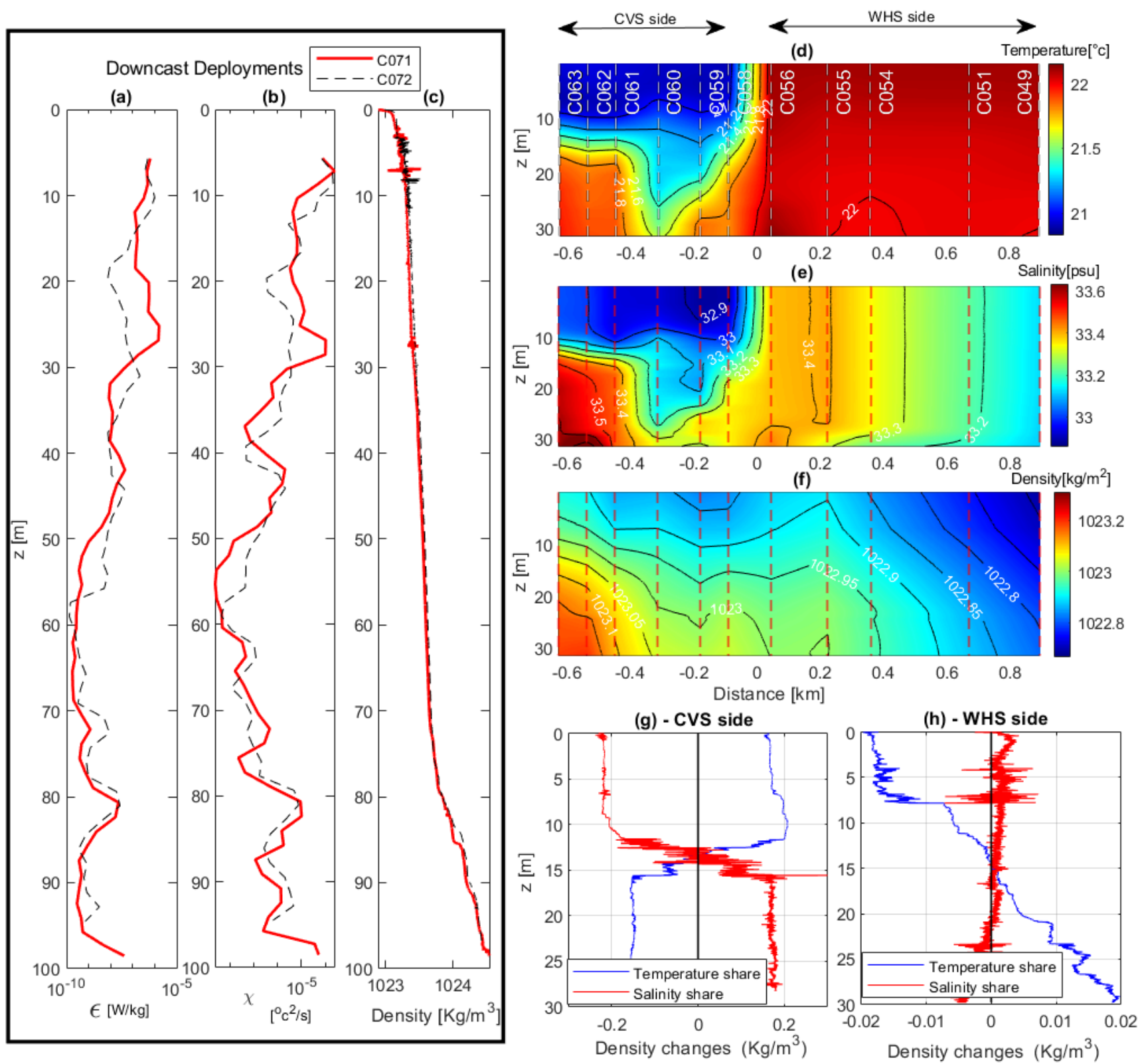

Figure 2. The vertical profiles of the VMP200 deployments on the cold-vertically stratified (CVS) Mississippi River water side are shown in a black box for downcasts C071 and C072. (a) Turbulent kinetic energy dissipation rate (TKED) (or $\epsilon$ ), (b) temperature dissipation (TD) (or $\chi$ ), and (c) water density. VMP200 derived transects of the front when the instrument was deployed using the upcast technique are shown in graphs (d) temperature, (e) salinity, and (f) density. The arrows above the (d) present the CVS and warm-horizontally stratified (WHS) Gulf of Mexico water sides. The vertical dashed lines present the location of deployments, and the zero distance shows the location of the front center. The relative contribution of salinity and temperature to density are shown on (g) the CVS (C060) and (h) WHS (C054) sides.

\subsection{The Salinity, Temperature, and Density Vertical and Horizontal Variability Obtained from the VMP200 Upcasts}

A more detailed picture of the front structure can be gleaned from the VMP200 series of vertical upcasts C049-C063, collected between 18:40 to 20:10 UTC. The horizontal resolution of the surface data are approximately $150 \mathrm{~m}$. In Figure $2 \mathrm{~d}-\mathrm{f}$, we present the front cross-section of the salinity (S), temperature (T), and density $(\rho)$ as a function of depth and horizontal distance from the front center. At the surface, the water properties such as $\mathrm{T}$ or $\mathrm{S}$ changed rapidly over a $200-\mathrm{m}$ distance, which corresponds to an approximate 
front width (Figure 2d,e). The cold front side, CVS, consisted of a vertically-stratified water colum (Figure 2f). The warm front side, WHS, was characterized by a set of tilted density layers (Figure $2 \mathrm{f}$ ) with a strong horizontal salinity gradient and relatively weak vertical salinity variability (Figure $2 \mathrm{e}$ ).

To compare the relative contribution of the $S$ and $T$ to density across the front, we plotted their relative contribution to density (McDougall et al. [30] method) using two selected VMP200 profiles, each from either the CVS or WHS side of the front (Figure 2g,h). The CVS side was characterized by large and compensated $\mathrm{T}$ and $\mathrm{S}$ contribution to density when compared to the WHS side. On the WHS side, the $S$ contribution to density was weaker with the temperature dominating the density variability. Each $\mathrm{T}$ and $\mathrm{S}$ vertical contribution to density had its contribution sign changed at around $15 \mathrm{~m}$ depth (Figure 2g,h).

\subsection{Cross Frontal TKED Vertical and Horizontal Variability}

The horizontal and vertical variability of the TKED inferred from uprising VMP200 profiles are in Figure 3a. The TKED within the upper layer possibly up to $9 \mathrm{~m}$, and across the front was enhanced relative to the lower depths and in addition, the CVS side has larger TKED values in comparison to the WHS side. The CVS side was characterized by a considerable value of the buoyancy frequency like a 'tongue' feature at 5-15 m depth (Figure $3 b$ ) and a relatively unstratified water column on the WHS side.

The VMP200 high-resolution density measurements permitted to measure Thorpe scale, $L_{T}=<L^{2}>^{1 / 2}$ [31,32], map (Figure 3c), where $L$ is Thorpe displacement. The estimated accuracy of the $L$, found from their distribution, was around $0.2 \mathrm{~m}$. Thorpe displacement is the water particle displacement needed to move the observed water particle from its current depth to form a stable density profile. That obtained displacement applies mostly to the shear-driven turbulence [32,33]. The Thorpe scale map (Figure 3c) shows large cross frontal asymmetry with the largest $L_{T}$ values on the CVS side. The CVS side is more likely to disperse surface neutrally buoyant contaminants down to $14.2 \mathrm{~m}$ at a $-0.4-\mathrm{km}$ distance from the front center (the black-dashed line in Figure 3c). Thus when considering the oil spill as a surface neutrally buoyant contaminant [34], the surface-bound oil will more likely be vertically dispersed on the CVS side.

\subsection{Turbulent Heat Flux and TD Variability along the Front}

Based on the VMP200 data, we estimated the surface vertical turbulent heat flux (THF) defined as: THF $\approx-\frac{1}{2} \rho c_{P} \chi / T_{z}[35,36]$, where the $c_{p}$ is water specific heat and the $T_{z}$ is temperature gradient. The surface is defined here as a part of the water column where the mean $T_{z}$ and the TD were measured by the VMP200 upcasts and represent depth average from the actual sea surface to depth $0.15 \mathrm{~m}$ and $0.5 \mathrm{~m}$ for $T_{z}$ and TD, respectively. Based on air-side measured parameters, Figure $1 \mathrm{~d}-\mathrm{e}$, we calculated the values of the sensible heat flux (SHF), and the latent heat flux (LHF) at the water surface by using the COARE 3.5 algorithm $[17,37]$ which is an update of COARE algorithms by Fairall et al. [38,39].

The averaged value of the surface heat fluxes and its direction for both side of the front combined with the TD cross-front map is presented in Figure 3d. The TD graph presented two layers on each side of the front (Figure 3d), which is the same as the TKED graph (Figure 3a). The first layer started from the water surface to a depth $z \approx 9 \mathrm{~m}$, and the second layer was created below a depth $z \approx 9 \mathrm{~m}$. Large TD values characterized the CVS side but lower surface THF values when compared to the WHS side. 


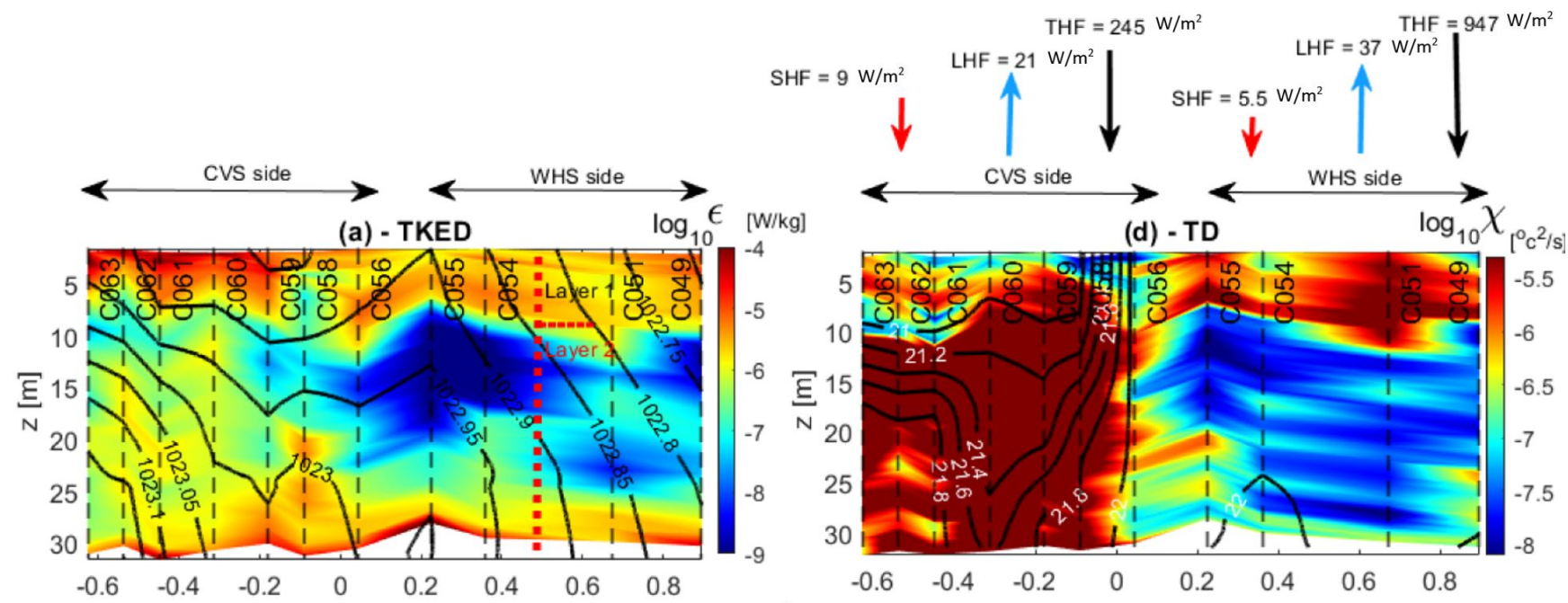

(b)

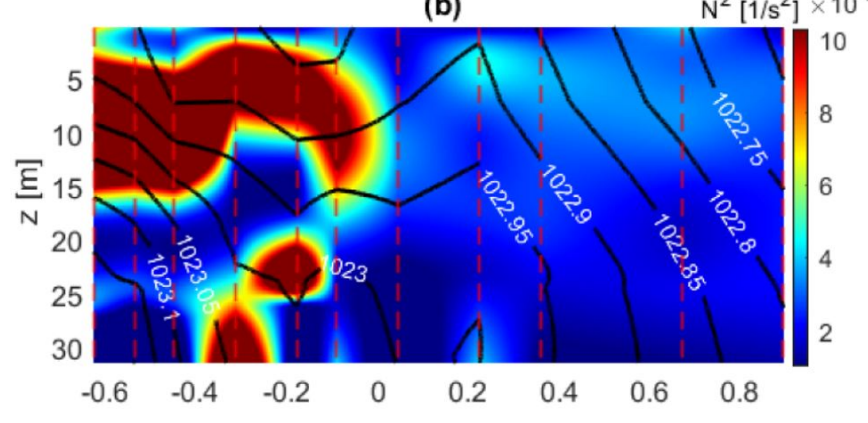

(e)
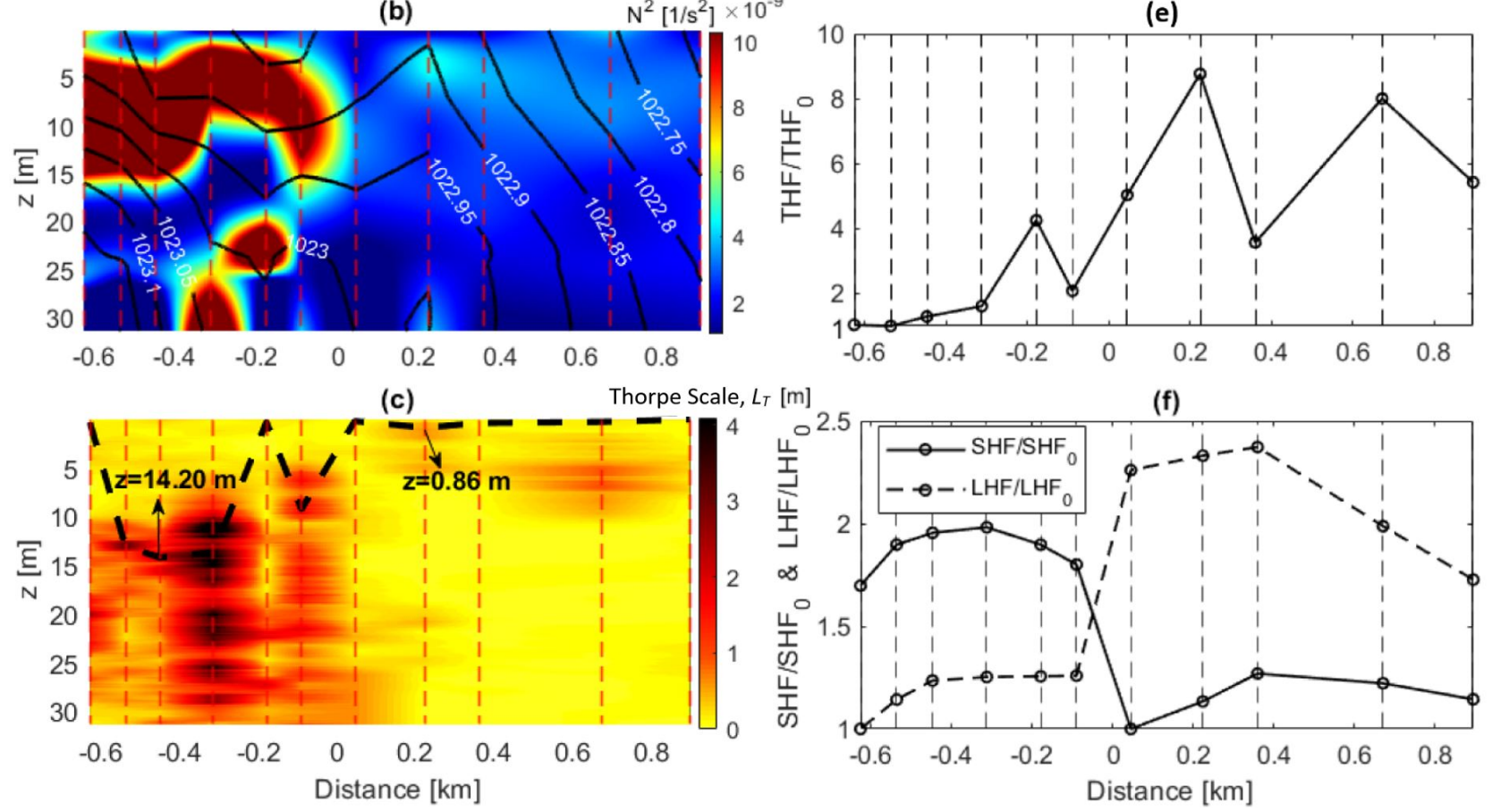

Figure 3. (a) The TKED vertical profiles across the front. The red-dashed lines separates the two observed layers of TKED. (b) The buoyancy frequency square, $N^{2}$, is shown. The black contour lines in $(\mathbf{a}, \mathbf{b})$ show the density. (c) The one meter-mean of the Thorpe sca, $L_{T}$. The black-dashed line presents the maximum depth that the water parcel can reach the water surface due to the vertical overturning. (d) The TD vertical profiles. The black counter lines of temperature are depicted. The direction and the average value of the water surface side sensible heat flux (SHF), latent heat flux (LHF), and turbulent heat flux (THF) are presented on both sides of the front by arrows (the arrows are not scaled). (e) The water surface THF of every upcast divided by its minimum value, $\mathrm{THF}_{0}$, is shown. (f) The SHF and LHF at the water surface divided by their minimum values named as $\mathrm{SHF}_{0}$ and $\mathrm{LHF}_{0}$, respectively, are shown. The direction and the average value of the $\mathrm{SHF}$, $\mathrm{LHF}$, and THF for graphs $(\mathbf{e}, \mathbf{f})$ are presented on both sides of the front by arrows (the arrows are not scaled) at the top of the graph $(\mathbf{d})$. The arrows shows the values of heat fluxes on the water side. The vertical black $(\mathbf{a}, \mathbf{d}-\mathbf{f})$ and red $(\mathbf{b}, \mathbf{c})$ dashed-lines present the location of the VMP200 deployments at different distances from the front center, shown by zero distance.

The measured horizontal asymmetry across the front of the surface THF, normalized to its lowest value, is presented in Figure 3e. The WHS side exhibited a larger surface THF by a factor of 4 than the CVS side, a striking anomaly and likely contributing to enhanced air side heat fluxes. The large values of the THF were mostly driven by the weaker near-surface mean temperature gradient and hence were larger on the weakly stratified WHS side (Figure 2f). 
The rest of the heat fluxes (SHF/LHF) vary only by a factor of 2 when crossing the front (Figure 3f). The air temperature was larger than the water temperature, and the airwater temperature difference was $\Delta T \approx 0.41{ }^{\circ} \mathrm{C}$ and $\Delta T \approx 1.56{ }^{\circ} \mathrm{C}$ on the WHS and CVS sides, respectively. The small temperature difference resulted in a small SHF of $\approx 9 \mathrm{~W} / \mathrm{m}^{2}$, positive value means that the heat inserted to the ocean, for the WHS side and $\approx 5.5 \mathrm{~W} / \mathrm{m}^{2}$ for the CVS side (Figure $3 \mathrm{~d}, \mathrm{f})$. The larger LHF $\approx-37 \mathrm{~W} / \mathrm{m}^{2}$ on WHS side in comparison to the CVS side, $\mathrm{LHF} \approx-21 \mathrm{~W} / \mathrm{m}^{2}$ (Figure $3 \mathrm{~d}, \mathrm{f}$ ) might be a result of higher relative humidity (Figure 1d) on the WHS side.

\section{Discussion}

\subsection{The Wave Effects on the Vertical TKED Distribution}

The atmospheric properties of relative humidity, air temperature, wind velocity, $\mathrm{H}_{s}$ (Figure 1d,e), and the solar insolation (not shown here) were relatively constant on either side of the front. The average $\mathrm{H}_{S}$ on the CVS side, $\mathrm{H}_{S}=1.20 \mathrm{~m}$, was larger than the WHS side, $\mathrm{H}_{S}=1.02 \mathrm{~m}$, due to slightly larger wind speed on the CVS side (Figure 1e). To assess surface wave effects on the vertical TKED profiles, we have compared the measured TKED profiles to the predicted vertical TKED, $\epsilon_{A M}(z)$, due to the action of surface waves [40] (Figure 4a). In general, the surface waves were observed [40] to follow the depth-dependent TKED as:

$$
\epsilon_{A M}=\left(2 K a_{1} u_{s_{0}}\right) u_{*}^{2} e^{-2 K z}
$$

$u_{s_{0}}=c_{p}(a K)^{2}$ is the wave Stoke drift at the ocean surface, here $a$ is wave amplitude. $a_{1}$ is a dimensionless constant associated with the surface waves, $a_{1}=3.75 b \pi \sqrt{\mathrm{H}_{s} / \lambda}$, where $b$ is an empirical constant ranging between $0-1$, and $\lambda$ is a dominant wavelength. The wavelength of the elevation spectrum maximum is considered as $\lambda$ in this paper. $u_{*}=\sqrt{\frac{\tau}{\rho}}$ is friction velocity where $\tau$ is wind stress.

The vertical TKED profiles normalized by $\epsilon_{A M}(z)$ presents converging the data from a depth of $5 \mathrm{~m}$ up to the water surface and approximately 6 times larger than inferred from Equation (1) (Figure 4a). The normalized TKED with $\epsilon_{A M}(z)$ had a better estimation than the wind scaling $\epsilon_{w}(z)=u_{*}^{3} / \mathrm{kz}$ [41], where $k$ is a von Karman constant, and the surface buoyancy flux $B_{0}$ [42] due to that the normalized ratio of $\epsilon / \epsilon_{A M}(z) \approx 6$ is smaller than $\epsilon / \epsilon_{w}(z) \approx 1.8 \times 10^{2}$ and $\epsilon / B_{0} \approx 1.3 \times 10^{2}$ over the depth $0-5 \mathrm{~m}$ (Figure $\left.4 \mathrm{~b}, \mathrm{c}\right)$. Given that the wave-generated turbulence predicts the TKED values better than other methods, it indicates the role of the surface wave on the TKED values compared to the other sources of surface turbulence.

We attribute the observed normalized TKED value departure from Equation (1), over $0-5 \mathrm{~m}$ depth, to the limitation of Equation (1) where the waves were characterized by parameters as dominant wave height and wavelength. The reality of the oceanic wave field is more complex since the upper few meters are likely dominated by shorter wind waves, while at depth, the dominant effect is the longer wavelength swell [40]. We then thus posit that the upper $5 \mathrm{~m}$ represents wave affected a portion of the underlying mixed layer. 

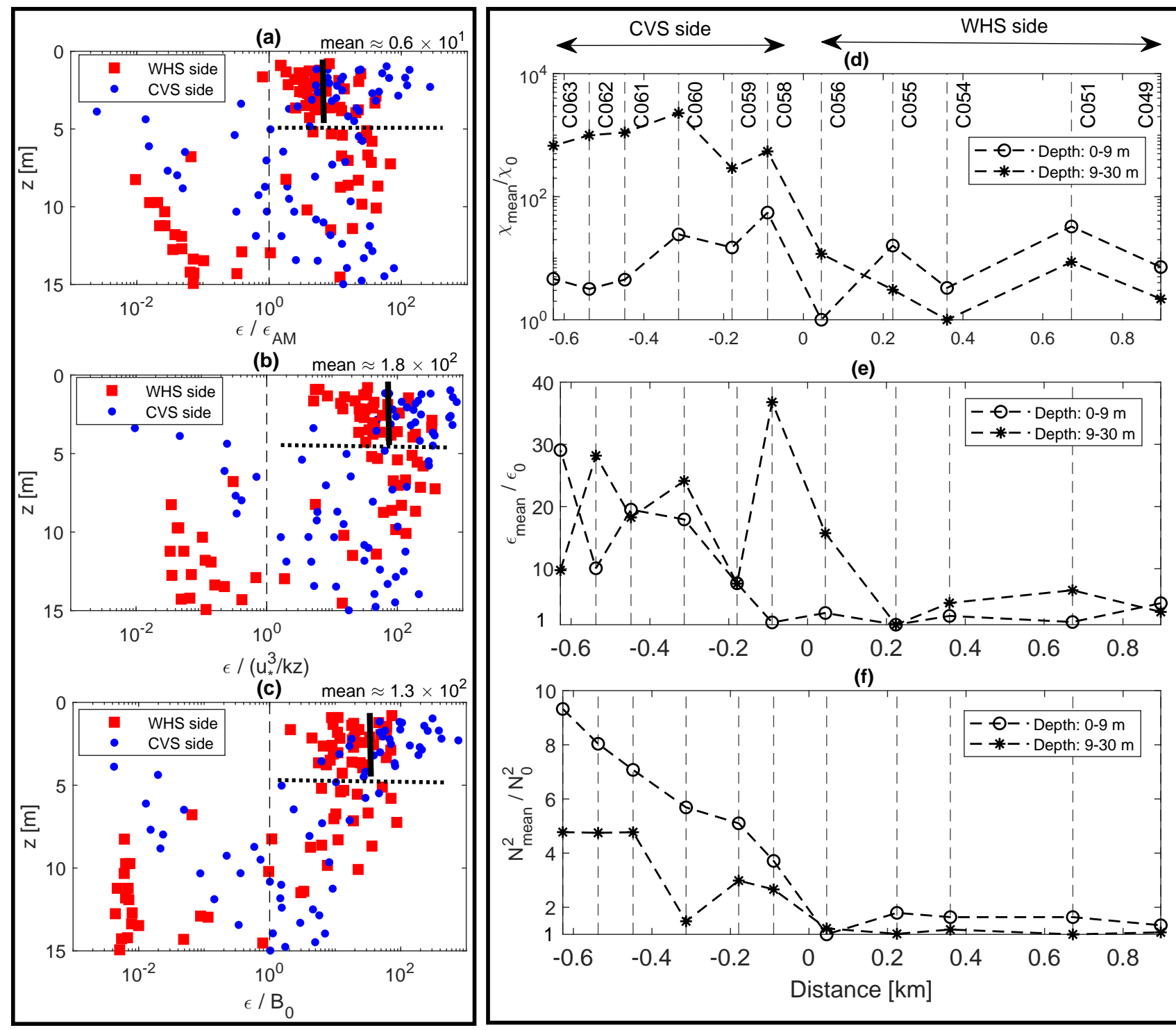

(e)
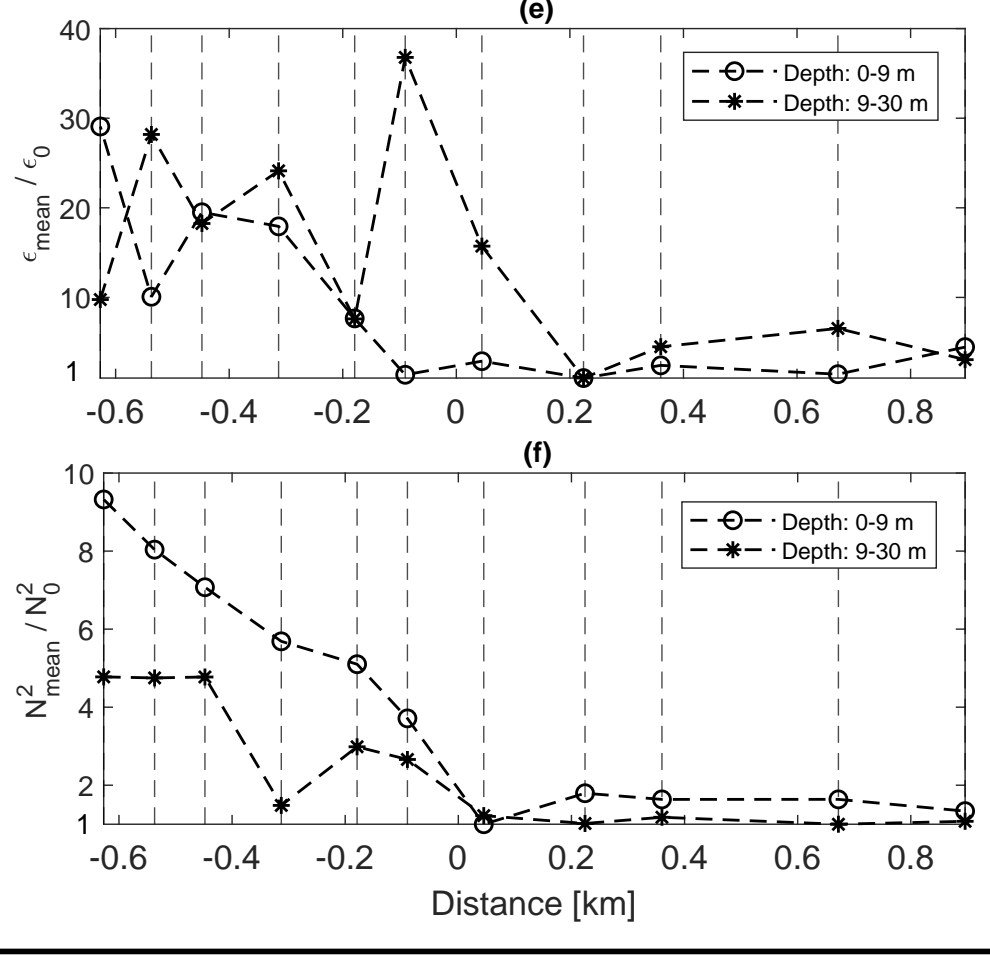

Figure 4. (a) The normalized TKED values with wave scaling [40], Equation (1), (b) wind scaling, $\epsilon_{w}(z)=u_{*}^{3} / \mathrm{kz},(\mathbf{c})$ and surface buoyancy flux scaling, $B_{0}$, methods. The average of the scaled TKED values from water surface to a depth of $5 \mathrm{~m}$ (shown by horizontal dashed line) is shown by vertical solid black lines in (a-c). The averaged water column properties across the front at two different depth ranges of $z=0-9 \mathrm{~m}$ (layer 1) and $z=9-30 \mathrm{~m}$ (layer 2) are presented in (d-f). (d) For both layers, the averaged TD value of every cast, $\chi_{\text {mean }}$, divided by the minimum averaged value of the layer, $\chi_{0}$, is shown. (e) The averaged TKED, $\epsilon_{\text {mean }}$, and (f) the averaged buoyancy frequency square, $N_{\text {mean }}^{2}$, normalized by their minimum averaged value for the layer showing by $\epsilon_{0}$ and $N_{0}^{2}$, respectively, are presented. The vertical dashed-lines in graphs (d-f) present the location of the VMP200 deployments at different distances from the front center, shown by zero distance.

\subsection{Layer Averaged Properties across the Front}

Now we are in a position to analyze layer averaged properties across the front. We have divided the water column into two distinct layers: The near-surface layer or first layer, affected by surface waves, and extending from $z=0$ to $5 \mathrm{~m}$ (Figure $4 \mathrm{a}$ ) and possibly up to a depth of $9 \mathrm{~m}$ depth (Figure 3a). The second layer, the mixed layer interior, includes the water column extending from $z=9$ to $30 \mathrm{~m}$. Within each layer, the average of the water column properties such as TD, TKED, and buoyancy frequency square, $N^{2}$ are normalized by their minimum value for that layer (Figure $4 \mathrm{~d}-\mathrm{f}$ )

The surface layer (0-9 m depth) averaged TD normalized to their lowest layer averaged value is roughly symmetrical around the front center (Figure $4 \mathrm{~d}$ ). The averaged 
and normalized TDs for the deeper layer (9-30 $\mathrm{m}$ depth) show strong TD cross frontal asymmetry with the TD values on the CVS side larger by a factor of 1000 than on the WHS side.

The CVS side presented 10 to 30 times larger TKED than the WHS side and irrespective of the layer depth (Figure 4e). The normalized $N^{2}$ (Figure $4 \mathrm{f}$ ) was larger on the CVS side by a factor of 5-10 when compared to the WHS side. The near-surface (averaged within 0-9-m depth) $N^{2}$ was the largest on the CVS side, as it likely reflects the effects of the near-surface stratification on that side.

We hypothesize that the internal wave (IW) breaking enhanced the TKED values on the second layer of the CVS side based on the observations of Oakey and Elliott [14], and Inoue et al. [15]. They found that the large TKED values within the front can be attributed to the IW breaking. A modeled IW dissipation, $\epsilon_{G H}$, calculated based on the work of Gargett and Holloway [43], is used as an estimate of IW-related TKED. The model contains a simple parametrization of the IWs generated TKED and assumes a constant value of the IWs energy density, $E_{d}$. Following that assumption, the $\epsilon_{G H}$ yields the IW field TKED as $\epsilon_{G H} \sim E_{d} N$ [43]. The ratio $\epsilon_{G H} / \epsilon_{\text {mean }}$ is vanishingly small in the upper $9 \mathrm{~m}$. It attains a value of $\epsilon_{G H} / \epsilon_{\text {mean }}=0.1$ on the CVS side within a 9-30 m depth interval, in other words, $10 \%$ of the measured TKED can be contributed to the IW breaking. It indicates that the IW presence may be a correct hypothesis however, there is no further proof in this paper. More detailed research is considered necessary to prove the hypothesis.

\section{Conclusions}

The observed frontal pattern in the world's largest marine ecosystem [44] indicates the importance of fronts in oceanic circulation and their role in the oceanic surface layer dynamics. Hence, this paper addressed turbulence variability across a submesoscale front in the GOM in the winter of 2016. The cross-section of the front revealed large horizontal variability of the surface heat flux, TD, and the ability of surface turbulent processes to remove neutrally buoyant surface-bound contaminants. We observed large surface THF frontal asymmetry with the WHS side, exhibiting up to a larger surface THF by 4 times. The rest of the heat fluxes (SHF/LHF) varied by only a factor of 2 when crossing the front. This asymmetry was likely reflected in the cross-front variability of atmospheric dynamics.

The cross-frontal observations demonstrated two vertical layers with the first layer spanning depths 0-9 $\mathrm{m}$ while the second layer extended over 9-30 $\mathrm{m}$. The cross frontal deep layer (9-30 m) averaged TD varied by a factor of 1000 and was larger on the CVS side. The near-surface layer $(0-9 \mathrm{~m})$ averaged TD was similar across the front. Within the deep and near-surface layers, the averaged TKED values were 10-30 times larger on the CVS side which was influenced by the cool Mississippi water when compared to the WHS side. By measuring the Thorpe scale, we posit that the CVS side surface-bound naturally buoyant particles were likely to experience eddies capable of submerging them up to a depth of $14.2 \mathrm{~m}$ with no such processes on the WHS side. The higher TKED on the vertical stratification side (or CVS side) has implications on the air-sea gas fluxes velocity, $K_{g} \sim \epsilon^{1 / 4}[45]$ and it is essential for the oil industry [46] due to higher turbulence enhancing the biodegradation of oil [47]. As fronts are common over the global ocean, the observed asymmetric response of the turbulence and their considerable variations across the front should be considered in the ocean-atmosphere climate system. The inaccurate boundary layer could cause a substantial climate prediction error. Future research should involve investigating if our observations are common in other oceanic fronts. In addition, such large values of THF across the front is suspicious and more detailed research is necessary to prove that the values of THF are correct. 
Author Contributions: Conceptualization, M.B. and D.B.; methodology, M.B., D.B., B.K.H. and T.O.; software, M.B.; validation, M.B., D.B. and B.K.H.; formal analysis, M.B.; writing-original draft preparation, M.B.; writing-review and editing, M.B., D.B., B.K.H., T.O. and M.S.; supervision, M.B. and D.B.; project administration, M.B. and D.B.; funding acquisition, D.B. and B.K.H. All authors have read and agreed to the published version of the manuscript.

Funding: This research was made possible in part by grants from the GOM Research Initiative and the National Science Foundation 1434670.

Institutional Review Board Statement: Not applicable.

Informed Consent Statement: Not applicable.

Data Availability Statement: Not applicable.

Acknowledgments: Thanks are given to all those who helped during the LASER experiment and Justin Trull for his help with the creation of the MATLAB plots. Data are publicly available through the GOM Research Initiative Information and Data Cooperative (GRIIDC) at https: // data.gulfresearchinitiative.org/data/R4.x265.237:0009 (accessed on 8 April 2021) (doi:10.7266/n7y7gw-vy06).

Conflicts of Interest: The authors declare no conflict of interest.

\section{Abbreviations}

The following abbreviations are used in this manuscript:

$\begin{array}{ll}\text { CVS } & \text { Cold-vertically stratified } \\ \text { WHS } & \text { Warm-horizontally stratified } \\ \text { TD } & \text { Temperature dissipation rate } \\ \text { TKED } & \text { Turbulent kinetic energy dissipation rate } \\ \text { GOM } & \text { Gulf of Mexico } \\ \text { LASER } & \text { LAgrangian Submesoscale ExpeRiment } \\ \text { CARTHE } & \text { Consortium for Advanced Research on Transport of Hydrocarbons in the Environment } \\ \text { VMP } & \text { Vertical microstructure profiler } \\ \text { THF } & \text { Turbulent heat flux } \\ \text { SHF } & \text { Sensible heat flux } \\ \text { LHF } & \text { Latent heat flux } \\ \text { IW } & \text { Internal wave }\end{array}$

\section{References}

1. Jaeger, G.S.; Mahadevan, A. Submesoscale-selective compensation of fronts in a salinity-stratified ocean. Sci. Adv. 2018, 4, e1701504. [CrossRef]

2. O'Neill, L.W.; Haack, T.; Chelton, D.B.; Skyllingstad, E. The Gulf Stream convergence zone in the time-mean winds. J. Atmos. Sci. 2017, 74, 2383-2412. [CrossRef]

3. Hall, I.R.; Starr, A.; Hemming, S.R.; Barker, S.; van der Lubbe, J.; Cartagena Sierra, A.; Berke, M.A.; Gruetzner, J.; Jiménez-Espejo, F.J.J.; Knorr, G.; et al. Surface and deep-water variability on the southern Agulhas Plateau: Interhemispheric links over the past 2 Ma. AGUFM 2019, 2019, PP52A-05.

4. Nagai, T.; Tandon, A.; Yamazaki, H.; Doubell, M.J.; Gallager, S. Direct observations of microscale turbulence and thermohaline structure in the Kuroshio Front. J. Geophys. Res. Ocean. 2012, 117. [CrossRef]

5. Luo, H.; Bracco, A.; Cardona, Y.; McWilliams, J.C. Submesoscale circulation in the northern Gulf of Mexico: Surface processes and the impact of the freshwater river input. Ocean Model. 2016, 101, 68-82. [CrossRef]

6. D'Asaro, E.; Lee, C.; Rainville, L.; Harcourt, R.; Thomas, L. Enhanced turbulence and energy dissipation at ocean fronts. Science 2011, 332, 318-322. [CrossRef] [PubMed]

7. Taylor, J.R. Accumulation and subduction of buoyant material at submesoscale fronts. J. Phys. Oceanogr. 2018, 48, 1233-1241. [CrossRef]

8. Liu, Y.; Yu, L.; Chen, G. Characterization of Sea Surface Temperature and Air-Sea Heat Flux Anomalies Associated With Mesoscale Eddies in the South China Sea. J. Geophys. Res. Ocean. 2020, 125, e2019JC015470. [CrossRef]

9. Petrenko, A.A.; Doglioli, A.M.; Nencioli, F.; Kersalé, M.; Hu, Z.; d'Ovidio, F. A review of the LATEX project: Mesoscale to submesoscale processes in a coastal environment. Ocean Dyn. 2017, 67, 513-533. [CrossRef]

10. Baschek, B. Air-Sea Gas Exchange in Tidal Fronts. Ph.D. Thesis, University of Victoria, Victoria, Canada, 2002. 
11. Walker, N.D.; Pilley, C.T.; Raghunathan, V.V.; D'Sa, E.J.; Leben, R.R.; Hoffmann, N.G.; Brickley, P.J.; Coholan, P.D.; Sharma, N.; Graber, H.C.; et al. Impacts of Loop Current frontal cyclonic eddies and wind forcing on the 2010 Gulf of Mexico oil spill. Monit. Model. Deep. Horiz. Oil Spill: A Rec.-Break. Enterp. Geophys. Monogr. Ser 2011, 195, 103-116.

12. Novelli, G.; Guigand, C.M.; Boufadel, M.C.; Özgökmen, T.M. On the transport and landfall of marine oil spills, laboratory and field observations. Mar. Pollut. Bull. 2020, 150, 110805. [CrossRef]

13. Nagai, T.; Tandon, A.; Yamazaki, H.; Doubell, M.J. Evidence of enhanced turbulent dissipation in the frontogenetic Kuroshio Front thermocline. Geophys. Res. Lett. 2009, 36. [CrossRef]

14. Oakey, N.; Elliott, J. Vertical temperature gradient structure across the Gulf Stream. J. Geophys. Res. 1977, 82, 1369-1380. [CrossRef]

15. Inoue, R.; Gregg, M.; Harcourt, R. Mixing rates across the Gulf Stream, part 1: On the formation of Eighteen Degree Water. J. Mar. Res. 2010, 68, 643-671. [CrossRef]

16. Jouanno, J.; Ochoa, J.; Pallàs-Sanz, E.; Sheinbaum, J.; Andrade-Canto, F.; Candela, J.; Molines, J.M. Loop Current frontal eddies: Formation along the Campeche Bank and impact of coastally trapped waves. J. Phys. Oceanogr. 2016, 46, 3339-3363. [CrossRef]

17. Shao, M.; Ortiz-Suslow, D.G.; Haus, B.K.; Lund, B.; Williams, N.J.; Özgökmen, T.M.; Laxague, N.J.; Horstmann, J.; Klymak, J.M. The variability of winds and fluxes observed near submesoscale fronts. J. Geophys. Res. Ocean. 2019, 124, 7756-7780. [CrossRef]

18. Bogucki, D.; Haus, B.K.; Shao, M. The Response of the Boundary Layer to Weak Forcing. In Ocean Sciences Meeting 2020; AGU: Washington, DC, USA, 2020.

19. McWilliams, J.C. Submesoscale currents in the ocean. Proc. R. Soc. A Math. Phys. Eng. Sci. 2016, 472, 20160117. [CrossRef]

20. D'Asaro, E.A.; Shcherbina, A.Y.; Klymak, J.M.; Molemaker, J.; Novelli, G.; Guigand, C.M.; Haza, A.C.; Haus, B.K.; Ryan, E.H.; Jacobs, G.A.; et al. Ocean convergence and the dispersion of flotsam. Proc. Natl. Acad. Sci. USA 2018, 115, 1162-1167. [CrossRef]

21. Barkan, R.; Molemaker, M.J.; Srinivasan, K.; McWilliams, J.C.; D'Asaro, E.A. The role of horizontal divergence in submesoscale frontogenesis. J. Phys. Oceanogr. 2019, 49, 1593-1618. [CrossRef]

22. D'Asaro, E.A.; Carlson, D.F.; Chamecki, M.; Harcourt, R.R.; Haus, B.K.; Fox-Kemper, B.; Molemaker, M.J.; Poje, A.C.; Yang, D. Advances in Observing and Understanding Small-Scale Open Ocean Circulation During the Gulf of Mexico Research Initiative Era. Front. Marine Sci. 2020, 7, 349.

23. Drennan, W.M.; Donelan, M.; Madsen, N.; Katsaros, K.; Terray, E.A.; Flagg, C. Directional wave spectra from a Swath ship at sea. J. Atmos. Ocean. Technol. 1994, 11, 1109-1116. [CrossRef]

24. Lueck, R.G.; Hertzman, O.; Osborn, T.R. The spectral response of thermistors. Deep Sea Res. 1977, 24, 951-970. [CrossRef]

25. Lueck, R.G.; Wolk, F.; Yamazaki, H. Oceanic velocity microstructure measurements in the 20th century. J. Oceanogr. 2002, 58, 153-174. [CrossRef]

26. Bogucki, D.J.; Haus, B.K.; Barzegar, M.; Shao, M.; Domaradzki, J.A. On the Nature of the Turbulent Energy Dissipation Beneath Nonbreaking Waves. Geophys. Res. Lett. 2020, 47, e2020GL090138. [CrossRef]

27. Bluteau, C.E.; Lueck, R.G.; Ivey, G.N.; Jones, N.L.; Book, J.W.; Rice, A.E. Determining mixing rates from concurrent temperature and velocity measurements. J. Atmos. Ocean. Technol. 2017, 34, 2283-2293. [CrossRef]

28. Metoyer, S.; Barzegar, M.; Bogucki, D.; Haus, B.K.; Shao, M. Measurement of small-scale surface velocity and turbulent kinetic energy dissipation rates using infrared imaging. J. Atmos. Ocean. Technol. 2021, 38, 269-282. [CrossRef]

29. de Boyer Montégut, C.; Madec, G.; Fischer, A.S.; Lazar, A.; Iudicone, D. Mixed layer depth over the global ocean: An examination of profile data and a profile-based climatology. J. Geophys. Res. Ocean. 2004, 109. [CrossRef]

30. McDougall, T.J.; Jackett, D.R.; Wright, D.G.; Feistel, R. Accurate and computationally efficient algorithms for potential temperature and density of seawater. J. Atmos. Ocean. Technol. 2003, 20, 730-741. [CrossRef]

31. Bogucki, D.; Haus, B.K.; Shao, M. The dissipation of energy beneath non-breaking waves. In Ocean Sciences Meeting 2020; AGU: Washington, DC, USA, 2020.

32. Jackson, L.; Hallberg, R.; Legg, S. A parameterization of shear-driven turbulence for ocean climate models. J. Phys. Oceanogr. 2008, 38, 1033-1053. [CrossRef]

33. Smith, J.A. A Comparison of Two Methods Using Thorpe Sorting to Estimate Mixing. J. Atmos. Ocean. Technol. 2020, 37, 3-15. [CrossRef]

34. Fingas, M.; Hollebone, B.; Fieldhouse, B. The density behaviour of heavy oils in freshwater: The example of the Lake Wabamun spill. In Emergencies Science and Technology Division, Environment Canada; Government of Canada: Toronto, ON, Canada, 2006.

35. Barzegar, M.; Bogucki, D.; Haus, B.K.; Shao, M. The Response of the Water Surface Layer to Internal Turbulence and Surface Forcing. J. Mar. Sci. Eng. 2021, 9, 217. [CrossRef]

36. Moum, J.N. Energy-containing scales of turbulence in the ocean thermocline. J. Geophys. Res. Ocean. 1996, 101, 14095-14109. [CrossRef]

37. Edson, J.B.; Jampana, V.; Weller, R.A.; Bigorre, S.P.; Plueddemann, A.J.; Fairall, C.W.; Miller, S.D.; Mahrt, L.; Vickers, D.; Hersbach, H. On the exchange of momentum over the open ocean. J. Phys. Oceanogr. 2013, 43, 1589-1610. [CrossRef]

38. Fairall, C.W.; Bradley, E.F.; Rogers, D.P.; Edson, J.B.; Young, G.S. Bulk parameterization of air-sea fluxes for tropical ocean-global atmosphere coupled-ocean atmosphere response experiment. J. Geophys. Res. Ocean. 1996, 101, 3747-3764. [CrossRef]

39. Fairall, C.W.; Bradley, E.F.; Hare, J.; Grachev, A.A.; Edson, J.B. Bulk parameterization of air-sea fluxes: Updates and verification for the COARE algorithm. J. Clim. 2003, 16, 571-591. [CrossRef]

40. Anis, A.; Moum, J. Surface wave-turbulence interactions. scaling $\varepsilon$ (z) near the sea surface. J. Phys. Oceanogr. 1995, 25, 2025-2045. [CrossRef] 
41. Esters, L.; Breivik, Ø.; Landwehr, S.; ten Doeschate, A.; Sutherland, G.; Christensen, K.H.; Bidlot, J.R.; Ward, B. Turbulence scaling comparisons in the ocean surface boundary layer. J. Geophys. Res. Ocean. 2018, 123, 2172-2191. [CrossRef]

42. Zahariev, K.; Garrett, C. An apparent surface buoyancy flux associated with the nonlinearity of the equation of state. J. Phys. Oceanogr. 1997, 27, 362-368. [CrossRef]

43. Gargett, A.E.; Holloway, G. Dissipation and diffusion by internal wave breaking. J. Mar. Res. 1984, 42, 15-27. [CrossRef]

44. Belkin, I.M.; Cornillon, P.C. Fronts in the world ocean's large marine ecosystems. ICES CM 2007, 500, 21.

45. Fredriksson, S.T.; Arneborg, L.; Nilsson, H.; Zhang, Q.; Handler, R.A. An evaluation of gas transfer velocity parameterizations during natural convection using DNS. J. Geophys. Res. Ocean. 2016, 121, 1400-1423. [CrossRef]

46. Loh, A.; Shankar, R.; Ha, S.Y.; An, J.G.; Yim, U.H. Stability of mechanically and chemically dispersed oil: Effect of particle types on oil dispersion. Sci. Total Environ. 2020, 716, 135343. [CrossRef] [PubMed]

47. Ramírez, J.; Moghimi, S.; Restrepo, J.M.; Venkataramani, S. Modelling the mass exchange dynamics of oceanic surface and subsurface oil. Ocean Model. 2018, 129, 1-12. [CrossRef] 